\title{
Utilização do adesivo fibrínico em LASIK
}

\author{
The use offibrin adhesive in LASIK
}

\author{
Hamleto Molinari ${ }^{1}$ \\ Claudio Muranaka²
}

\section{RESUMO}

Objetivo: Avaliar a utilização do adesivo fibrínico em LASIK, com o intuito de minimizar as complicações relacionadas ao disco. Métodos: Foi realizado LASIK em 312 pacientes (624 olhos). Ambos os olhos foram operados no mesmo dia, sendo utilizada a técnica convencional em um olho e a técnica com o uso do adesivo fibrínico no olho contralateral. Resultados: $\mathrm{O}$ uso do adesivo fibrínico demostrou uma redução significativa das complicações relacionadas ao disco. Comentários: A utilização do adesivo fibrínico mostrou também ser muito útil em casos de LASIK pós-ceratotomia radial, adesão de disco com corte total e hemostasia na borda do disco.

Descritores: Adesivo tecidual de fibrina/uso terapêutico; Ceratomileuse assistida por excimer laser in situ

\section{INTRODUÇ̃̃̃O}

A cirurgia refrativa pela técnica do LASIK vem se difundindo rapidamente entre todos os cirurgiões oftalmológicos em detrimento do PRK e da Ceratotomia radial.

O LASIK necessita de uma perfeita interação entre o cirurgião, microceratótomo e excimer laser, o cirurgião necessita de uma curva de aprendizagem longa, associada a facilidade de funcionamento, manejo e precisão do microceratótomo + excimer laser ${ }^{(36)}$. $\mathrm{O}$ que todos os cirurgiões que estão iniciando nesta técnica temem, são as complicações ${ }^{(9,24,27)}$, visto que estas, apesar de serem mais raras, geralmente são de maior gravidade.

As principais dúvidas surgem quanto à prevenção das complicações cirúrgicas, dentre elas, destacamos as relacionadas à confecção e adesão do disco corneano.

Com o objetivo de reduzir estas complicações relacionadas a confecção e adesão do disco corneano, tais como: perda, deslocamento, epitelização da interface, dobras e estrias, etc., descreveremos a seguir uma variação da técnica por nós proposta que é a utilização do uso do adesivo fibrínico em LASIK.

\section{Adesivo fibrínico}

O adesivo fibrínico foi utilizado pela primeira vez por Brown \& Nantz, em 1944, para fechamento de feridas em córneas de coelhos. Desde então, o adesivo biológico tem sido muito usado em diversos procedimentos cirúrgicos.

O adesivo de fibrina homóloga foi aprovada pela FDA para ser utilizada nos EUA a partir do final da decada de $80^{(3)}$.

$\mathrm{O}$ adesivo biológico é composto de fibrinogênio e trombina. $\mathrm{O}$ fibrinogênio é o precursor direto da fibrina insolúvel, estrutura fundamental do coágulo sanguíneo. A trombina é uma enzima proteolítica que ativa o fibrinogênio, rompendo-o em dois fibrinopeptídeos A e B, formando desta
Estudo realizado no Molinari Instituto de Oftalmologia $\mathrm{S} / \mathrm{C}$ Ltda (MIO).

${ }^{1}$ Diretor do Molinari Instituto de Oftalmologia - Adjunto Doutor pela Universidade Federal de São Paulo.
${ }^{2}$ Médico do Molinari Instituto de Oftalmologia.

Endereço para correspondência: R. Bento de Andrade, 379 - São Paulo (SP) CEP 04503-011. E-mail:secretaria (a)molinari.com.br 
maneira, o monômero de fibrina ${ }^{(13,32)}$. Através de ligações hidrogeniônicas ocorre a polimerização da molécula, formando o polímero de fibrina que é o coágulo.

$\mathrm{O}$ adesivo biológico (Tissucol) é preparado a partir de "pools" de plasmas humanos. As unidades de plasma utilizadas são obtidas de doadores rigorosamente selecionados e controlados, e são todos não reativos em testes para o antígeno anti-HB e anticorpos HIV e anti-HCV e os valores ALT determinados.

Para aumentar a segurança na eliminação de risco e de infecções virais são utilizados processos especiais de tratamento pelo vapor.

O adesivo biológico quando comparado a outro adesivo como o cianocrilato, apresenta a vantagem de ser totalmente absorvível ${ }^{(32)}$, além de ser considerado o melhor entre os adesivos teciduais ${ }^{(31)}$.

Suas principais indicações são: hemostasia, vedação, adesão e selagens teciduais e apoio à cicatrização ${ }^{(32,35)}$.

Em cirurgia oftalmológica, o adesivo de fibrinogênio foi testado em diversos procedimentos cirúrgicos (experimentais) tais como: cirurgias maculares ${ }^{(28,34)}$, descolamento de retina ${ }^{(6,8,10)}$, cirurgias de estrabismo ${ }^{(11)}$, cirurgias anti-glaucomatosas ${ }^{(2,16,29)}$, cirurgia de catarata ${ }^{(17-19,31)}$, facoemulsificacao com tunel escleral $^{(1,5,21)}$, cirurgia orbitária ${ }^{(3)}$, perfurações corneanas ${ }^{(4,25)}$, plástica ocular ${ }^{(7,12)}$, conjuntiva ${ }^{(12)}$, ceratotomia radial ${ }^{(14)}$, transplante lamelar ${ }^{(22-23)}$ transplante penetrante ${ }^{(5,15,25)}$ esclera $^{(20)}$ e vias lacrimais $^{(33)}$.

\section{MÉTODOS}

Todos os procedimentos foram realizados numa mesma clinica, utilizando o Excimer Laser Aesculap Med Tec Mel 60 e dois microceratótomos (Chiron e Summit).

Adesivo fibrínico de origem humana liofilizado $\left(\right.$ Tissucol $^{\circledR}$ ) Composição completa:

Solução $I$ - O pó liofilizado, que após a reconstituição resulta em $1 \mathrm{ml}$ de solução de Tissucol, contém:

1 - Proteína coagulável $=75$ a $115 \mathrm{mg}$, composta de Fibrinogênio humano $=70$ a $110 \mathrm{mg}$ e fibronectina plasmáti$\mathrm{ca}=2 \mathrm{a} 9 \mathrm{mg}$

2 - Fator XIII $10-50 \mathrm{U}$

3 - Plasminogênio 40 a 120 micra grama

Solução II - Solução de aprotinina (bovina) $=3000 \mathrm{KIU} / \mathrm{ml}$

Solução III - Trombina 500 Humana Liofilizada, $1 \mathrm{ml} \mathrm{da}$ solução reconstituída contém 500 UI (ação rápida).

Reconstituída contém em $1 \mathrm{ml}$ $500 \mathrm{UI}$

Solução IV - Solução de Cloreto de Cálcio $=40 \mathrm{mmol} \mathrm{CaCl}_{2} /$ litro

O "kit" Tissucol é composto por quatro soluções, na preparação, mistura-se a solução I e II para constituir a solução de Tissucol e mistura a solução III e IV para a constituição da solução de trombina. O "kit" apresenta um aplicador duplo que mistura a solução de Tissucol com a solução de trombina durante a aplicação, o qual irá resultar no adesivo fibrínico solidificado.
Foram realizados LASIK em 312 pacientes, sendo todos os procedimentos bilaterais (ambos os olhos) no mesmo dia, utilizando a técnica rotineira em um dos olhos e utilizando o adesivo fibrínico no olho contralateral, a correção foi aleatória para miopia, astigmatismo e hipermetropia sendo evitadas as altas ametropias e anisometropias. Utilizou-se a técnica rotineira no olho dominante e a técnica com o adesivo fibrínico no olho não dominante.

Todos os pacientes foram informados previamente sobre 0 procedimento e submetidos ao consentimento da cirurgia.

As graduações variam de:

Miopia de $-1,00 \mathrm{DE}$ até $-10,00 \mathrm{DE}$, astigmatismo de $-0,50$ até $-4,00 \mathrm{DC}$ e hipermetropia de $+1,00 \mathrm{DE}$ até $+4,00 \mathrm{DE}$.

\section{Técnica}

Os procedimentos foram realizados com uso de anestesia tópica com colírio de tetracaína a 10\%. Realizou-se assepsia de face, fixação dos cílios com o auxílio da fita adesiva estéril e colocação do blefarostato.

1) Realizou-se a marcação do eixo visual com marcador assimétrico e como corante utilizou-se a violeta de genciana, que possibilita a correta reposição do disco corneano.

2) Em seguida, fixou-se o anel de sucção, e foi feita a tonometria, e o encaixe da cabeça do microceratótomo.

3) Corte com o microceratótomo.

4) Levantou-se o disco e, secou-se com o auxílio de Merocel.

5) Aplicação do excimer laser.

6) Lavagem com solução salina balanceada e auxílio de Merocel.

7) Recolocação do disco.

8) Secagem do disco com utilização de esponja e ventilação por 2 minutos.

9) Remoção da fita adesiva e do blefarostato.

\section{Técnica do LASIK convencional:}

1 - Aplicação do microceratótomo realizando-se o corte do disco.

2 - Levantamento do disco.

3 - Aplicação do excimer laser.

4 - Reposição do disco.

5 - Secagem por 2 minutos.

\section{Técnica do LASIK com uso do adesivo:}

1 - Técnica convencional.

2 - Aplicação do adesivo nas bordas, procurando deixar a zona óptica de $6 \mathrm{~mm}$ livres.

3 - Recolocação do disco com lavagem simultânea associada à massagem suave para remoção do excesso de adesivo.

4 - Secagem da borda do disco com utilização de esponja (Merocel) e secagem sem ventilação por 40 segundos.

5 - Remoção da fita adesiva e do blefarostato.

Tempo de seguimento: 6 meses 


\section{RESULTADOS}

O percentual de complicações nos olhos em que foram submetidos ao tratamento LASIK com a utilização do adesivo fibrínico, foi de 1,6\% (5/312 olhos); significantemente menor $(\mathrm{p}<0,001)$ que o percentual de complicações nos olhos que o tratamento de LASIK com procedimento convencional: 12,2\% (38/312 olhos). O "odds-ratio" estimado foi de 8,51, com intervalo de confiança de $95 \%$ : $[3,15 ; 24,97]$, indicando que a chance de complicação no método convencional é aproximadamente oito vezes maior. Na tabela 1 estão descritas as complicações encontradas em cada tratamento.

\begin{tabular}{|lcccccc|}
\hline \multicolumn{5}{|c|}{$\begin{array}{c}\text { Tabela 1. Complicações encontradas em cada tratamento } \\
\text { LASIK com } \\
\text { procedimento } \\
\text { convencional }\end{array}$} & $\begin{array}{c}\text { LASIK com } \\
\text { adesivo } \\
\text { fibrínico }\end{array}$ & Total \\
Complicação & $\mathbf{N}$ & $\%$ & $\mathbf{N}$ & $\%$ & $\mathbf{N}$ & $\%$ \\
Deslocamento de disco & 6 & 1,92 & 1 & 0,32 & 7 & 1,12 \\
Epitelização da interface & 5 & 1,60 & 1 & 0,32 & 6 & 0,96 \\
Dobras no disco & 3 & 0,96 & 0 & 0,00 & 3 & 0,48 \\
Estrias & 21 & 6,73 & 1 & 0,32 & 22 & 3,53 \\
Disco livre & 2 & 0,64 & 0 & 0,00 & 2 & 0,32 \\
Disco irregular & 1 & 0,32 & 2 & 0,64 & 3 & 0,48 \\
\hline
\end{tabular}

Nos casos de LASIK com adesivo, observou-se:

a) Ao exame biomicroscópico a córnea estava transparente sem sinal de adesivo em 24 horas.

b) Recuperação visual mais rápida por melhores condições epiteliais.

c) Pequeno número de complicações.

Em ambos os grupos os pacientes saíam da sala de cirurgia com os dois olhos abertos. Só houve um caso de deslocamento do disco com adesivo, pois logo após a cirurgia o paciente coçou o olho de uma forma vigorosa.

Em um olho no qual houve excesso de cola deixada de forma intencional (abertura de C. R.) houve total reabsorção e transparência corneana em 6 dias.

\section{Pós-operatório}

O pós-operatório nada difere da técnica convencional. Foi prescrito antibiótico 4 vezes ao dia, antiinflamatóio não hormonal 4 vezes ao dia e lubrificante ocular.

Quando necessário, indicou-se a instilação de fluometalona 4 vezes ao dia mantendo a medicação por um período de 10 dias.

Realizou-se acompanhamento de rotina com 30,90 e 120 dias.

\section{Complicações}

As complicações do uso do adesivo fibrínico podem ocorrer tanto no período intra-operatório quanto no pós-operatório.

\section{Intra-operatório:}

1 - Excesso de adesivo na interface, deve-se removê-lo completamente com lavagem abundante e esptulagem da superfície com solução salina balanceada.

2 - Excesso de adesivo na borda cirúrgica: pode-se remover o excesso endurecido da borda com o auxílio de tesoura de Vannas e pinça delicada.

3 - Adesivo endurecido na interface; ocorre quando o adesivo seca antes do tempo previsto. Deve-se remover o adesivo com o auxílio de uma pinça e repetir novamente todo o procedimento.

4 - Formação de dobras do disco, ocorre quando o disco foi mal reposicionado, devemos levantar o disco novamente, lavar a superfície para remover o adesivo e repetir todo o processo novamente.

\section{Pós-operatório:}

1 - Opacidades na interface; deve-se ao excesso de adesivo localizado em determinados pontos, nestes casos, basta aguardar um período de cerca de 3 a 7 dias que todo o excesso será reabsorvido.

2 - Excesso de adesivo na borda da ferida cirúrgica; devese remover com o auxílio de uma tesoura de Vannas e uma pinça delicada, pois o paciente costuma ter queixa de sensação de corpo estranho.

3 - Risco de infecção; pode ocorrer quando o adesivo preparado exceder o período de 4 horas na seringa.

\section{DISCUSSÃO}

Em ambos os grupos, os pacientes sairam da sala cirúrgica com ambos os olhos abertos. Só se observou um caso de deslocamento do disco no grupo II, onde o paciente refere ter traumatizado o olho com o dedo. Nos casos de reoperação pósceratotomia radial, coloca-se excesso de cola na interface, com o objetivo de maior aderência, havendo completa reabsorção ao longo de sete a 10 dias.

Em dois casos de corte completo do disco observados no grupo II, o paciente foi tratado com o excimer laser e a utilização do adesivo fibrínico foi de fundamental importância no resultado.

Neste estudo ficaram evidentes os benefícios do adesivo biológico no LASIK, não tendo sido observada nenhuma complicação relativa ao seu uso.

Ficou demonstrado assim que, a imediata, boa e segura aderência do disco previne as complicações mais freqüentemente encontradas.

Pode-se ainda, recomendar um estudo criterioso para a utilização do adesivo fibrínico também em enxertos lamelares e penetrantes.

É de grande valia também o seu uso em casos de hemorragias quando há neovasos corneanos e cirurgia pós ceratotomia radial, pois evita a epitelização da interface através das incisões da ceratotomia, se estas se abrirem. 


\section{CONCLUSÕES}

Neste estudo ficaram evidentes os benefícios da variação da técnica tradicional utilizando-se o adesivo biológico, não tendo sido apresentada nenhuma complicação relativa ao seu uso e à sua capacidade de prevenir as complicações usualmente encontradas como já descritas anteriormente.

Ficou demonstrado assim que, a imediata, boa e segura aderência ao estroma previne as complicações em potencial.

Em um caso no qual houve corte incompleto do disco, foi colocado adesivo no bordo, e nova cirurgia foi realizada em 7 dias.

Pode-se, portanto recomendar estudo criterioso para a utilização do adesivo também em enxertos lamelares e penetrantes.

\section{ABSTRACT}

Purpose: To evaluate the use of fibrinogen adhesive in LASIK for minimization of flap complications. Method: LASIK was performed in 312 patients (624 eyes). Both eyes were operated on the same day, one eye with the conventional technique and the other with adhesive application. Results: A significant decrease of flap complications was shown. Conclusion: The use of fibrinogen adhesive showed to be efficient in the decrease of flap complications. Comments: This technique seems to be useful in LASIK following radial keratotomy and astigmatism keratotomy, in gluing free cap, and in interface hemostasis.

Keywords: Fibrin tissue adhesive/therapeutic use; Keratomileusis, laser in situ

\section{REFERÊNCIAS}

1. Alio JL, Mulet E, Sakla HF, Gabbi F. Efficacy of synthetic and biological bioadhesives in scleral tunnel phacoemulsifications in eyes with high myopia. J Cataract Refract Surg 1998;24:983-8.

2. Asrani SG, Wilensky JT. Managemant of bleb leaks after glaucoma filtering surgery. Use of autologous fibrin tissue glue as an alternative. Ophthalmology 1996;103:294-8.

3. Bartley GB, Maccafrey TV. Crioprecipitated fibrinogen (fibrin glue) in orbital surgery. Am J Ophthalmol 1990;109:227-8.

4. Bonatti AJ, Stefano JT, Matheus LC, Oliveira GA, Suzuki H, Kara-Jose N. Desenvolvimento do adesivo tecidual fibrínico para uso experimental em perfurações corneanas. Arq Bras Oftalmol 1990;58:354-6.

5. Brittain GP, Rostron CK, Morton DB, Rees JE. The use of a biological adhesive to achieve sutureless. Eye 1989;3(Pt1):56-63.

6. Brown AL, Nantz FA. The use of fibrin coagulum fixation in ocular surgery: in retinal detachment. Trans Am Acad Ophthalmol Otolaryngol 1949;54:126-30.

7. Caldato R, Ortolan JR, Lima VM, Marchi WJ, Rocha EM, Ambrósio LE, Bizzacchi JA. Cola fibrina em cirurgia plastica ocular [abstract]. Arq Bras Oftalmol [periódico em CD-ROM] 1994;57(4).

8. Coleman DJ, Luca BC, Fleischman JA, Dennis PH, Chang S, Iwamoto T, Nalbandian RM. A biologic tissue adhesive for vitreoretinal surgery. Retina 1988;8:250-6.
9. Davidorf JM, Zaldivar R, Oscherow S. Results and complications of laser in situ keratomileusis by experienced surgeons. J Refract Surg 1998;14: 114-22.

10. Emmerich KH, Busse H, Slezak H, Steinkogler F. Experimental transvitreal fibrin gluing of the retina. Klin Monatsbl Augenheilkd 1989;194:42-7.

11. Erbil H, Sinav S, Kandemir B. Experimental study on the use of the fibrin sealants in strabismus surgery. Turk J Pediatr 1991;133:111-6.

12. Friess HG, Hesse W. Fibrin gluing in ophthalmic surgery. Wien Klin Wochernschr 1986;98:346-7.

13. Fungmann EA. Viabilização do preparo e da aplicação do adesivo de fibrina [dissertação]. Paraná: Universidade do Paraná;1993.

14. Goins KM, Khadem J, Majmudar PA, Ernest JT. Phothodynamic biologic tissue glue to enhance corneal wound healing after radial keratotomy. J Cataract Refract Surg 1997;23:1331-8.

15. Goins KM, Khadem J, Majmudar PA. Relative strength of phtodynamic biologic tissue glue in penetrating keratoplaty in cadaver eyes. J Cataract Refract Surg 1998;24:1566-70.

16. Grewing R, Mester U. Fibrin sealant in the management of complicated hypoton after trabeculectomy. Ophthalmic Surg Lasers 1997;28:124-7.

17. Grewing R, Mester U. Radial suture stabilized by fibrin glue to correct preoperative against-the-rule astigmatism during cataract surgery. Ophthalmic Surg 1994;25:446-8.

18. Henrick A, Gaster RN, Silvertone PJ. Organic tissue glue in the closure of cataract incisions. J Cataract Refract Surg 1987;13:551-3.

19. Hernel B. Studies on the use of tissues adhesives in cataract microsurgery. Polim Med 1980;10:3-18.

20. Karel I, Dolezalova J. Use of tissucol, a tissue glue, in reconstructive surgery of large scleral defects. Cesk Oftalmol 1991;47:219-23.

21. Kim JC, Bassage SD, Kempski MH, del Cerro M, Park SB, Aquarella JV. Evaluation of tissue adhesive in closure of scleral tunnel incisions. J Cataract Surg 1995;21:320-5.

22. Kim MS, Kim JH. Effects of tissue adhesive (Tisseel) on corneal wound healing in lamellar keratoplasty in rabbits. Korean J Ophthalmol 1989;3:14-21.

23. Klemen UM, Freyler H, Prskavec FH, Dinges HP. Healing of lamellar corneal grafts in rabbit eyes after gluing with highly concentrated fibrinogen. Albrecht Von Graafes Arch Klin Exp Ophthalmol 1979;210:261-7.

24. Lam DSC. Management of severe flap wrinkling or dislodgment after laser in situ keratomileusis. J Cataract Refarct Surg 1999;25:1441-7.

25. Maguen E, Nesburn A, Macy JI. Combined use of sodium hyaluronate and tissue adhesive in penetrating keratoplasty of corneal perforations. Ophthalmic Surg 1984;15:55-7.

26. Mester U, Zuche M, Rauber M. Astigmatism after phacoemulsification with posterior chamber lens implantation: small incisions technique with fibrin adhesive for wound closure. J Cataract Refract Surg 1993;19:616-9.

27. Stulting RD, Car JD, Thompson KP, Waring Go $3^{\text {rd }}$ Wiley WM, Walker JG. Complications of laser in situ keratomileusis for the correction of myopia. Ophthalmology 1999;106:13-20.

28. Olsen TW, Sternberg P Jr, Capone A Jr, Martin DF, Lim JI, Grossniklaus $\mathrm{HE}$ et al. Macular hole surgery using thrombin-activated fibrinogen and selective removal of the internal limiting membrane. Retina 1998;18:322-9.

29. O'Sullivan F, Dalton R, Rostron CK. Fibrin glue: a alternative method of wound closure in glaucoma surgery. J Glaucoma 1999;5:366-70.

30. Perez EP, Viramontes B, Schor P, Miller D. Factor affecting corneal strip stroma-to-stroma adhesion. J Refract Surg 1998;14:460-2.

31. Shigemitsu T, Majima Y. The utilization of a biological adhesive for wound treatment: comparisson of suture, self-sealing sutureless and cyanoacrylate closure in the tensile streagh test. In Ophthalmol 1996-97;20:323-8.

32. Siedentop KH, Harris DM, Sanchez B, Ham K. Autologus fibrin tissue adhesive. Laryngoscope 1985;95:1074-6.

33. Steinkogler FJ, Moser E. Canaliculo-cystostomy using the fibrin glue technics. Forstschr Ophthalmol 1989;86:76-7.

34. Tilanus MA, Deutman AF. Full-thickness macular holes treated with vitrectomy and tissue glue. Int Ophthalmol 1994-95;18:355-8.

35. Zauberman H, Hemo I. Use of fibrin glue in ocular surgery. Ophthalmic Surg 1988;19:132-3.

36. Molinari H, Nascimento E. Ceratomileusis In: Belfort Junior R, Kara-Jose N. Cornea: Clínica-Cirúrgica. São Paulo: Roca; 1997. p. 541-8. 